\title{
Perceptions on climate change and its impact on livelihoods in Hwange district, Zimbabwe
}

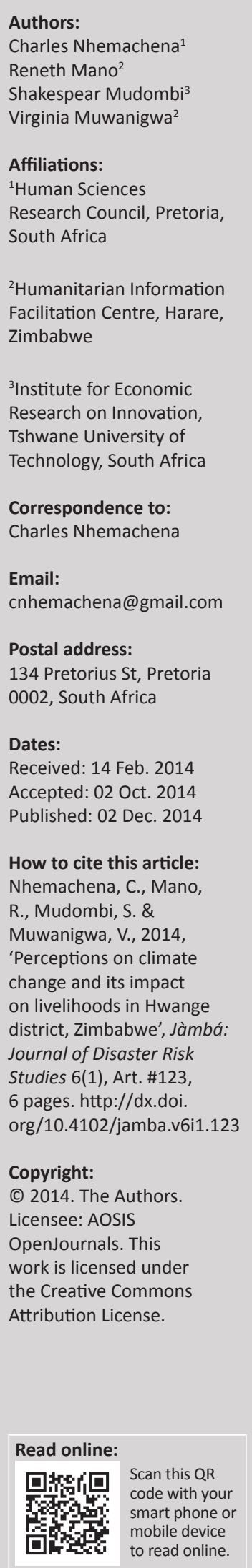

This study investigated perceptions of rural communities on climate change and its impacts on livelihoods. The research was conducted in the semi-arid Hwange district in Matebeleland North province of Zimbabwe. The perceptions were compared with empirical evidence from climatic studies on trends on temperature and rainfall, and impacts on livelihoods in the country and region. The findings from the current study are generally in agreement with those of other studies that indicate changes in the climate, especially in terms of rainfall. This largely applies to short-term periods; however, for long-term periods it is difficult to accurately relate rural community perceptions to changes in rainfall over time. Despite perceived changes and impacts of climate change on local livelihood activities, mainly agriculture, there are multiple stressors that the communities face which also affect their livelihoods. Further evidence-based research is required to disentangle climate change impacts on livelihoods, including livelihood impacts arising from interactions of climate and non-climatic factors.

\section{Introduction}

The Intergovernmental Panel on Climate Change (IPCC)'s Fourth Assessment Report indicates that increases in warming and drying in Africa can impact agriculture by reducing crop yields by almost half by 2020 (IPCC 2007). This will have profound adverse impacts on the already vulnerable and poor communities that rely on climate-sensitive livelihood sources like agriculture and natural systems.

Climate change models for southern Africa indicate that the region will face increased challenges due to projected changes in climate (Hulme et al. 2005). Further evidence (e.g. IPCC 2007; Tadross, Hewiston \& Usman 2005; Tadross et al. 2009) predict rainfall reductions and increased rainfall variability for most parts of southern Africa. In addition, southern Africa has recently been experiencing recurrent droughts (including mid-season droughts) (Moyo et al. 2012), and these experiences together with other extreme climatic events are expected to continue (Twomlow, Steyn \& Du Preez 2006). The region is generally projected to face further warming, drying and extreme climatic conditions, although these will vary spatially across the region.

Brown et al. (2012) argue that evidence from climate change projections in southern Africa (such as increased intensity and frequency of extreme events) is supported by recent trends in climate in the region. Farmers in Zimbabwe are mostly reliant on rain-fed agriculture, and natural systems which are sensitive to climate change are vulnerable to current and expected changes in climate (Chagutah 2010). Failure to address climate change threatens to reverse developmental gains across various sectors and worsen the vulnerability of local systems and the national economy. Therefore climate change adaptation is of critical importance for the Zimbabwean economy.

How rural communities in general and farmers in particular perceive climate change is a prerequisite for them to make informed decisions on local adaptation (Maddison 2007; Slegers 2008). These perceptions are usually informed by farmers and rural communities' own experiences of how climate change impacts on their livelihoods (Slegers 2008). Noticing climate change alone is not enough to make farmers adapt to climate change and other factors.

Evidence from Maddison (2007) on 11 African countries indicates that even if farmers accurately perceive climate change, some may still fail to adapt optimally because of limited access to information, adaptation technology options, markets and budgetary resources, amongst other factors. This shows the importance of ensuring that rural communities have the means and resources to implement the various potential optimal adaptation strategies at their disposal to address current and expected climate change impacts on their livelihoods.

However, climate change adaptation is a two-stage process: (1) the initial stage is perceiving that changes in climate have occurred and (2) making decisions to adopt a particular measure or not 
(Maddison 2007). Based on this and the above arguments, identifying how farmers perceive climate change is critical to helping to inform policy decisions on adaptation grounded on local perspectives and current autonomous adaptation strategies.

In rain-fed and marginal regions in Zimbabwe decisions to invest in farms are greatly influenced by farmers' and rural communities' perceptions of climate-induced risks (Moyo et al. 2012). Therefore this article sought to investigate rural communities' perceptions of climate change and its impacts on livelihoods. The perceptions were compared with empirical evidence from climatic studies on trends on temperature and rainfall and impacts on livelihoods in the country and region.

\section{Research method and design Description of the study setting}

The Hwange district situated in Matebeleland North province of Zimbabwe falls under natural regions IV and $\mathrm{V}$, characterised by very high temperatures ranging from $25{ }^{\circ} \mathrm{C}$ and above and annual rainfall of less than $450 \mathrm{~mm}$. The potential for agriculture is low due to the unfavourable climatic conditions, poor soil and other limiting natural and socio-economic factors (D. Mandongwe [Forestry Commission, Victoria Falls] pers. comm., 17 January 2012). The district is vulnerable to current and expected changes in climate, exacerbated by low adaptation capacity and climate change interaction with other stressors already being experienced in the area, such as food insecurity, poverty and ecosystem degradation (Hassan \& Nhemachena 2008).

These rural communities rely on dry land agricultural and natural ecosystem-based tourism activities. Rural tourism is sustained by the close proximity of the Victoria Falls, one of the main international and domestic tourist destinations in Zimbabwe. Another significant tourist attraction in the district is Hwange National Park. This presents off-farm income-generating and livelihood opportunities for rural agricultural communities, including the production and selling to tourists of non-farm forest products such as wood carvings, tonga baskets, mats, and rural eco-tourism. Forest timber resources adapted to the semi-arid agro-climatic region of Hwange are more resilient to climate change than the drought-prone crop and/or livestock farming system in the same region (D. Mandongwe [Forestry Commission, Victoria Falls] pers. comm., 17 January 2012).

\section{Data collection and analysis}

The empirical analyses were based on data from a crosssectional survey conducted in Hwange district in February 2012. The primary data were collected in a number of ways. The quantitative data were collected through a farm household survey, whilst the qualitative data were collected using focus group discussions (FGDs) and key informant interviews. Secondary data on weather patterns were sourced from the Meteorological Service Department.
The use of different data collection methods increased the comprehensiveness of information gathered as well as allowing for triangulation of findings.

The study focused on rural communities' climate change perceptions and their adaptation responses. FGDs collected information on livelihood activities, community perceptions to changes in climate and their impacts, as well as community responses. Three FGDs were conducted (one in each ward), comprising about 20-25 mixed (in terms of gender, age, and resource endowments) rural community members.

Fieldwork activities were facilitated by the Hwange District Administration, Environment Africa (a local non-governmental organisation) and local agricultural extension officers. The cross-sectional survey covered three purposefully selected wards (Chidobe, Nemananga, and Jambesi), from which a sample of 150 randomly selected households were interviewed. Household interviews using a semi-structured questionnaire were conducted to gather both qualitative and quantitative information to complement the data collected from the FGDs.

The sampled households provide a fair representation of livelihood activities in the district. Key informant interviews were conducted with extension staff, development workers, and local leaders who comprised chiefs and village heads. The data were entered and analysed in Microsoft Excel and Stata. Descriptive statistics, mainly frequencies, were used for empirical analyses. Empirical climate studies were used to validate farmers' perceptions and implications on livelihoods.

\section{Ethical considerations}

The respondents for this research were not subjected to any risk that could harm them physically or mentally. There were no potential physical and psychological dangers that the respondents were exposed to. Clearance to undertake the research in the study area was sought with the relevant authorities, Hwange district Administrator and local traditional leaders. Feedback meetings were conducted after the research was finished to provide the communities with the findings and recommendations from the project. The rights of respondents as participants were emphasised and observed throughout the project. The decision to participate in the study was voluntary. The respondents had the right to decide not to participate, or to stop taking part at any time without providing a reason for doing so, without any undue effects. In this study, none of the respondents refused to participate.

In addition to consent from the gatekeepers, individual informed consent to participate in the study was sought before each interview. This process involved the enumerators outlining the objectives and purpose of the research. The respondents were also assured that the data would be properly handled to ensure their safety and the confidentiality of respondents. They were assured that the date data were 
and would only be accessed by the researchers and would be solely used for research purposes.

Respondents were notified that there are no monetary benefits and rewards from participating in the study. However, the benefit to the community was through feedback meetings conducted in September 2012 at which the findings were shared with the community stakeholders.

\section{Trustworthiness}

The findings from the research were triangulated with other sources such as relevant published reports and articles, and the feedback meetings also helped to validate the findings.

\section{Results and discussion Perceptions on changes in climate}

The research assessed rural communities' perceptions of changes in climate variables (mainly rainfall, temperature and extreme events) over the past $5-10$ years or more, as well as the impacts of such changes. The characterisation of past climatic conditions in recent years and decades was done in FGDs. Results on perceptions indicated that Hwange district does not receive adequate rainfall. In addition, the amount and patterns of rainfall were perceived as changing.

FGDs results showed that the district was experiencing fluctuations in the amount of rainfall; some years were receiving normal rainfall, others below and others above normal rainfall. The overall reported trend in the district was a general decline in the amount of rainfall received as well as its increased variability. There were reports of incidents of very high rainfall intensity that lasted for short periods. In addition, the agricultural season was reported to have shortened compared to the past. The starting dates of rains were reported to have shifted from October to late November and sometimes to December. Moreover, the magnitude and frequency of dry spells that occur within a season have increased. These mid-season droughts affected critical growth stages of crops, which in some cases resulted in complete crop failure. Perceptions on temperature indicated an increasing trend over the years. For instance, it was indicated that the summer of 2011 was very hot, which resulted in some people dying due to heat stress.

Household survey results supported FGD findings and showed that most of the interviewed rural community members had noticed and were aware of climate change and variability. As for the FGD results, respondents reported increases in temperature in the area in recent years. On rainfall, perception results (Figure 1) indicate that about $89 \%$ of the farmers reported observing changes in rainfall patterns. Most of the respondents $(87 \%)$ indicated that the most observed and perceived pattern was that precipitation showed a decreasing and increased variability trend.

The results are similar to those of other studies conducted in other semi-arid environments in Zimbabwe (Moyo et al.

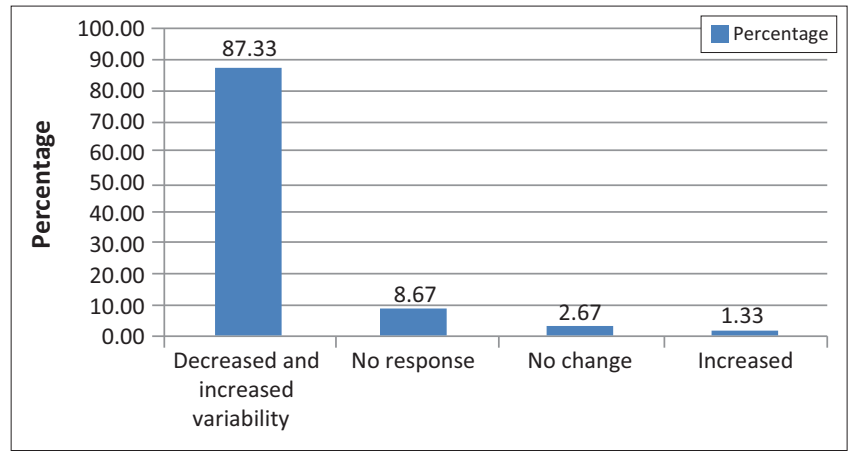

Source: Authors' own construction

FIGURE 1: Perceptions of changes in rainfall patterns.

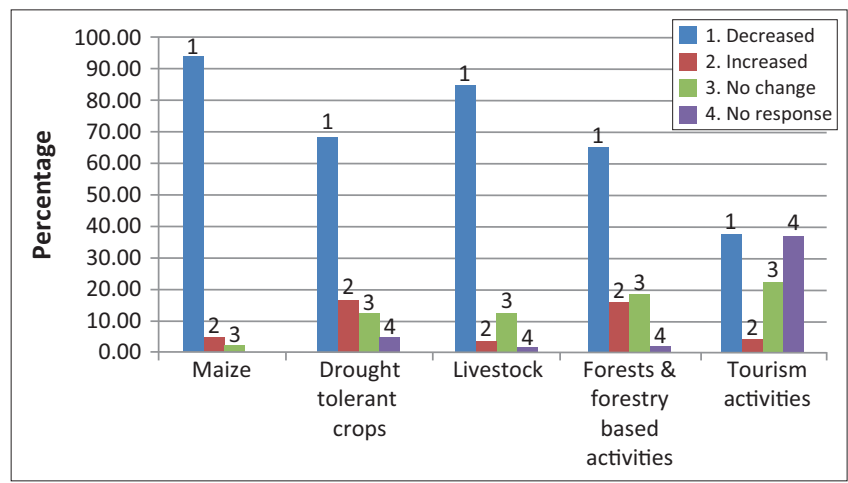

Source: Authors' own construction

FIGURE 2: Perceptions of impacts of changes in climate on agriculture and tourism activities.

2012) and other parts of Africa (Maddison 2007; Slegers 2008; Rao et al. 2011; Nyanga et al. 2011). For instance, farmers' perceptions in Hwange (Ndlovu/Kachechete and Jambezi wards) and Masvingo reported changes in climate in the last 10-20 years, through changes in rainfall (especially more erratic as well as reduced amounts) and rising temperatures that adversely impacted on crop and livestock production (Moyo et al. 2012). In an African study involving 11 African countries Maddison (2007) found that many farmers believed that temperatures had risen whilst rainfall had decreased.

\section{Perceived impacts on livelihood activities of the rural communities}

Rural communities in Hwange reported having noticed changes in climate. The communities perceived that these changes contributed to adverse impacts on their livelihood sources, which are mainly agricultural-based and to some extent also based on non-farm tourism-based activities (Figure 2). The results indicate that more than $64 \%$ of the rural communities in Hwange perceived that the changing climatic conditions have adverse impacts on the main agricultural crops (maize, drought-tolerant crops (sorghum and millet), livestock, and forestry-based activities). Most of the perceived adverse impacts are on crop production. In addition, the incidence of pests was reported to be rising due to increasing temperatures. This, combined with inconsistent and declining rainfall, was reported to have devastating impacts on both crop and livestock production. 
About $37 \%$ reported that tourism activities are negatively affected by the perceived changes in climate. However, from these results the general trend of perceptions was that changes in climatic conditions in addition to multiple other factors (such as poverty, HIV and/or AIDS, food insecurity) are having negative impacts on the main rural livelihood sources in Hwange district. Further discussions with the farmers pointed to lack of timely information and resources to buy agricultural inputs as critical constraints limiting their agricultural activities and any potential adaptation to climate and other changes.

The findings were confirmed by key informant interviews which emphasised that there is evidence that agriculture, forestry and other natural systems were threatened by changes in climate such as increases in drying, warming, droughts, weeds, pests and diseases. This is expected to result in reduced productivity of the livelihood sources of rural communities, such as agriculture, forests, and wetlands. The challenge for the communities is to build resilience to adapt and to use their natural resources sustainably.

\section{Comparing rural community perceptions and empirical climate change evidence}

Empirical climatic evidence in Zimbabwe shows contrasting views on climate change, particularly for rainfall. A number of studies conducted in the country show that rainfall is decreasing due to climate change (e.g. Brown et al. 2012; Chenje, Sola \& Paleczny 1998; Chamaillé-Jammes, Fritz \& Murindagomo 2007; Government of Zimbabwe 1996; Makarau 1995; Tadross et al. 2009; Unganai 1996). Evidence from Zimbabwe shows that droughts and floods have increased in frequency and intensity, including increasing changes in the timing and onset of rains (Government of Zimbabwe 1996; Tadross et al. 2009; Unganai 1996). Mean annual rainfall is reported to have declined by up to $10 \%$ on average in the 20th century, which is about $1 \%$ per decade, and mostly in recent years (Chenje et al. 1998; Unganai 1996). In addition, empirical evidence from ChamailléJammes et al. (2007) showed that droughts had increased in Hwange National Park in terms of their rate of occurrence and intensity. Despite spatial differences across the country, climatic evidence shows that Zimbabwe is getting warmer, with more unpredictable rainfall patterns (Brown et al. 2012).

However, Mazvimavi (2008) argues that available evidence does not indicate that droughts have changed in frequency and intensity from 1892 to 2000. For example, he found contrasting results showing that the tenth percentile of the October, November and December rainfall showed historical increases for Hwange, as opposed to the findings of Chamaillé-Jammes et al. (2007). In a separate study empirical evidence in Hwange showed that meteorological droughts tend to occur in every 2-3 years (Moyo et al. 2012). Moyo et al. (2012) showed that over long-term periods, climate data fail to show the evidence perceived by farmers, except for temperature. In addition, farmers' perceptions were found to be generally comparable to the rainfall data observed in recent years. These results imply that farmers can accurately perceive change and climate variability and impacts on their livelihoods for short time periods. The results for perceptions on temperature were in agreement with actual trends in observed temperatures indicating a clear increase in temperature.

According to Mazvimavi (2008) perceived increases in the frequency and intensity of droughts may be based on comparison of the 1980s and 1990s, which were drier than the 1970s. However, this argument may be true for old farmers and respondents, and may not be true for many of the young respondents currently living in the rural communities who did not live through the wet 1970s and have only experienced the recent events, where recurring droughts have been a major phenomenon. Furthermore, the findings of Moyo et al. (2012) indicate that in the shortterm, rural communities are able to recall their experiences and can accurately tell the changes they have experienced in climatic conditions. The findings from the current study are generally in agreement with those of Moyo et al. (2012) and other earlier studies for short-term changes, especially in the past decade. However, for long-term period, it is difficult to accurately relate rural community perceptions to changes in rainfall over time.

Furthermore, Mazvimavi (2008) argues against attributing losses in crop yields and livestock production to decreasing rainfall. He asserts that the losses result from other factors, such as poor agricultural practices (for instance, growing unsuitable crop varieties, land and range land degradation). In a separate study Richardson (2007) argues that inappropriate government policies are the main contributing factor to the fall in crop and livestock production in Zimbabwe in the 2000s. Despite arguments against attributing agriculture performance failure to changes in climate, the effects of increased frequency and severity of rainfall variability and droughts during the same period cannot be underestimated.

Despite the findings from other studies questioning attribution of the decline in agricultural productivity and impacts on livelihoods to climate change in Zimbabwe, various empirical studies have shown that changes in climate are already having substantial negative impacts on agriculture and livelihoods, which are expected to continue if climate change is not addressed. For example, related research in Zimbabwe and other regions in the continent are experiencing huge losses to their livelihoods from changes in climatic conditions (e.g. Dinar et al. 2008; Kurkulasuriya et al. 2006; Nhemachena, Hassan \& Kurukulasuriya 2010; Nhemachena 2009).

Kurukulasuriya et al. (2006) and Nhemachena et al. (2010) show that the agricultural sector in southern Africa is very vulnerable to changes in climate. Mendelsohn, Dinar and Dalfelt (2000) predicted losses of $0.4 \%-1.3 \%$ of gross domestic product (GDP) in southern Africa due to climate change. 
In another study Kurukulasuriya and Mendelsohn (2008) predicted reductions in net crop revenues for southern Africa of $12 \%-17 \%$ although some pockets are expected to benefit from climate change. Predicted changes in climate threaten agricultural activities and livelihoods in the country.

The empirical findings on climate change impacts in the region are comparable to perceived impacts on livelihood activities by communities in Hwange district. The findings from discussions with the communities showed that a semiarid region like Hwange has low potential for agriculture due to the unfavourable climatic conditions, poor soil and other limiting natural and socio-economic factors. Although the communities perceived climate change to have resulted in negative impacts on their livelihood activities, there are multiple stressors that these communities have been and are experiencing, including poverty, HIV and/or AIDS, food insecurity and unemployment. It is therefore important for adaptation interventions to consider a whole developmental approach in improving livelihoods and adaptive capacities of communities.

\section{Limitations of the study}

Although the communities perceived climate change to have resulted in negative impacts on their livelihood activities, there are multiple stressors that the communities have been and are experiencing, such as endemic poverty and food insecurity. Further evidence-based research is required to disentangle impacts of changes in climate on livelihoods, including the impacts of the interactions of climate and nonclimatic factors.

\section{Recommendations}

Despite international efforts to address climate change, local impacts on livelihoods are inevitable and most rural communities are already experiencing the burden. This means local communities, such as those in Hwange district, must proactively invest in strategies to adapt in order to reduce expected climate change impacts on their livelihoods. There is a need to collectively support (e.g. government, business, and civil society) rural communities to enhance their adaptive capacity. However, further evidence-based research is required to disentangle impacts of changes in climate on livelihoods, including the impacts of the interactions of climate and non-climatic factors.

\section{Conclusion}

This article investigated perceptions of rural communities on climate change and its impacts on livelihoods. The research was conducted in Hwange district, located in Matebeleland North province of Zimbabwe. The perceptions were compared with empirical evidence from climatic studies on trends on temperature and rainfall and impacts on livelihoods in the country and region.

The empirical results showed that there was generally a high awareness of the changing climate amongst the respondents, with $89 \%$ of them reporting observing changes in rainfall patterns. Findings from the current study are generally in agreement with those from studies that indicate changes in the climate, especially in terms of rainfall. This largely applies to short-term periods; however, for long-term periods it is difficult to accurately relate rural community perceptions to changes in rainfall over time.

\section{Acknowledgements}

This work was supported by the Global Change SysTem for Analysis, Research and Training (START), the donors Climate and Development Knowledge Network and Climate Change, Agriculture and Food Security under the Global Environmental Change in African research programme grant, 2011. The authors are also grateful to Hwange District Administration and Environment Africa for assistance during the fieldwork.

\section{Competing interests}

The authors declare that they have no financial or personal relationship(s) that may have inappropriately influenced them in writing this article.

\section{Authors' contributions}

C.N. (Human Sciences Research Council) conceptualised the article content and compiled the first draft. R.M. (Humanitarian Information Facilitation Centre), S.M. (Tshwane University of Technology) and V.M. (Humanitarian Information Facilitation Centre) revised and made conceptual contributions, additions, and refined the article.

\section{References}

Brown, D., Chanakira, R.R., Chatiza, K., Dhliwayo, M., Dodman, D., Masiiwa, M., et al., 2012, Climate change impacts, vulnerability and adaptation in Zimbabwe, Climate Change Group, International Institute for Environment and Development, London. (International Institute for Environment and Development Climate Change Working Paper No. 3).

Chagutah, T., 2010, Climate Change Vulnerability and Preparedness in Southern Africa: Zimbabwe Country Report, Heinrich Boell Stiftung, Cape Town.

Chamaillé-Jammes, S., Fritz, H. \& Murindagomo, F., 2007, 'Detecting climate changes of concern in highly variable environments: Quantile regressions reveal that droughts worsen in Hwange National Park, Zimbabwe', Journal of Arid Environments 71, 321-326. http://dx.doi.org/10.1016/j.jaridenv.2007.05.005

Chenje, M., Sola, L. \& Paleczny, D. (eds), 1998, The State of Zimbabwe's Environment 1998, Government of the Republic Zimbabwe, Ministry of Mines, Environment and Tourism, Harare.

Dinar, A., Mendelsohn, R., Hassan, R. \& Benhin, J., 2008, Climate Change and Agriculture in Africa: Impacts Assessment and Adaptation Strategies, Earthscan, London.

Government of Zimbabwe, 1996, Initial National Communications to the UNFCCC Ministry of Environment and Tourism, Harare.

Hassan, R. \& Nhemachena, C., 2008, 'Adaptation to climate change in Africa: Multinomial choice analysis of determinants of farm strategies', African Journal of Agricultural and Resource Economics 2(1), 83-104.

Hulme, M., Doherty, R., Ngara, T. \& New, M., 2005, 'Global warming and African climate change: A re-assessment', in P.S. Low (ed.), Climate Change and Africa, pp. 29-40, Cambridge University Press, Cambridge. http://dx.doi.org/10.1017/ CB09780511535864.013

Intergovernmental Panel on Climate Change (IPCC), 2007, 'Summary for Policymakers', in M.L. Parry, O.F. Canziani, J.P. Palutikof, P.J. van der Linden \& C.E. Hanson (eds.), Climate Change 2007: Impacts, Adaptation and Vulnerability. Contribution of Working Group II to the Fourth Assessment Report of the Intergovernmental Panel on Climate Change, n.p., Cambridge University Press, Cambridge.

Kurukulasuriya, P. \& Mendelsohn, R., 2008, How will climate change shift agroecological zones and impact African agriculture?, World Bank, Washington, DC. (World Bank Policy Research Working Paper 4717). 
Kurkulasuriya, P., Mendelsohn, R., Hassan, R., Benhin, J., Deressa, T., Diop, M. et al., 2006, 'Will African agriculture survive climate change?' World Bank Economic Review 20(3), 367-388. http://dx.doi.org/10.1093/wber/Ihl004

Maddison, D., 2007, The perception of and adaptation to climate change in Africa, Development Research Group, Sustainable Rural and Urban
Development Team, the World Bank, Washington, DC. (Policy Research Working Development
Paper 4308).

Makarau, A., 1995, 'Intra-seasonal oscillatory models of the southern Africa summer circulation', PhD thesis, University of Cape Town, South Africa.

Mazvimavi, D., 2008, 'Investigating possible changes of extreme annual rainfall in Zimbabwe', Hydrology and Earth System Sciences Discussions 5, 1765-1785. http://dx.doi.org/10.5194/hessd-5-1765-2008

Mendelsohn, R., Dinar, A. \& Dalfelt, A., 2000, Climate change impacts on African agriculture, Preliminary analysis prepared for the World Bank, World Bank, Washington, DC

Moyo, M., Mvumi, BM., Kunekweguta, M., Mazvimavi, K., Craufurd, P. \& Dorward P., 2012, 'Farmer perceptions on climate change and variability in semi-arid Zimbabwe in relation to climatology evidence', African Crop Science Journal 20(2), 317-335.

Nhemachena, C., Hassan, R. \& Kurukulasuriya, P., 2010, 'Measuring the economic impact of climate change on African agricultural production systems', Climate Change Economics 1(1), 33-55. http://dx.doi.org/10.1142/ S2010007810000066

Nhemachena, C., 2009, 'Agriculture and future climate dynamics in Africa: Impacts and adaptation options', PhD thesis, Dept. of Agricultural Economics, Extension and Rural Development, University of Pretoria.
Nyanga, P.H., Johnsen, F.H., Aune, J.B. \& Kalinda, T.H., 2011, 'Smallholder farmers' perceptions of climate change and conservation agriculture: Evidence from Zambia', Journal of Sustainable Development 4(4), 73-85. http://dx.doi. org/10.5539/jsd.v4n4p73

Rao, K.P.C., Ndegwa, W.G., Kizito, K. \& Oyoo, A., 2011, 'Climate variability and change: Farmer perceptions and understanding of intra-seasonal variability in rainfall and associated risk in semi-arid Kenya', Experimental Agriculture 47, 267-291. http:// dx.doi.org/10.1017/S0014479710000918

Richardson, C.J., 2007, 'How much did drought matter? Linking rainfall and GDP growth in Zimbabwe', African Affairs 106(424), 463-478. http://dx.doi.org/10.1093/afraf/ adm013

Slegers, M.F.W., 2008, “If only it would rain": Farmers' perceptions of rainfall and drought in semi-arid central Tanzania', Journal of Arid Environments 72 2106-2123. http://dx.doi.org/10.1016/j.jaridenv.2008.06.011

Tadross, M.A., Hewiston, B.C. \& Usman, M.T., 2005, 'The interannual variability of the onset of the maize growing season over South Africa and Zimbabwe', Journal of Climate 18, 3356-3372. http://dx.doi.org/10.1175/JCLI3423.1

Tadross, M.A., Suarez, P., Lotsch, A., Hachigonta, S., Mdoka, M., Unganai, L. et al., 2009 , 'Growing-season rainfall and scenarios of future change in southeast Africa: Implications for cultivating maize', Climate Research 40, 147-161. http://dx.doi. org/10.3354/cr00821

Twomlow, S.J., Steyn, JT. \& Du Preez, C.C., 2006, 'Dryland farming in Southern Africa', in G.A. Peterson, P.W. Unger \& W.A. Payne (eds.), Dryland Agriculture, 2nd edn., Chapter 19, pp. 769-836, Agronomy Monograph No. 23, American Society of Agronomy, Madison, Wisconsin.

Unganai, S.L., 1996, 'Historic and future climatic change in Zimbabwe', Climate Research 6, 137-145. http://dx.doi.org/10.3354/cr006137 